\title{
HISTÓRIA E POLÍTICAS*
}

\section{Gilberto Hochman}

A história importa? Essa é uma pergunta cuja resposta de cientistas políticos, na trilha de economistas e sociólogos da política, tem sido, nas últimas duas décadas, crescentemente incisiva e insistentemente positiva, ainda que longe de unânime. Tanto o substantivo "história", como o adjetivo "histórico", passaram a freqüentar mais o vocabulário corrente da disciplina, ainda que se saiba que a história esteve mais presente na formação e nos caminhos das ciências sociais (Abrams, 1982; Reis, 1998). É no campo disciplinar da sociologia que esse diálogo tem sido mais constante e persistente, de onde derivam a expressão "virada histórica das ciências sociais" (McDonald, 1996), a constatação de que vivemos

* A Elisa Pereira Reis, que me introduziu no tema das relações entre ciências sociais e história, e a Simone Kropf, que me ensinou a conviver, mais tranqüilamente, com as inúmeras interseções da vida e da academia. uma "era de ouro da sociologia macro-histórica" (Collins, 1999) ou estamos em uma "segunda ou terceira onda" da sociologia histórica (Adams et al., 2005). Parte dessa reflexão tem produzido fortes intersecções com a análise histórica comparada e com as análises de políticas públicas (Ashford, 1992; Mahoney e Rueschemeyer, 2003).

Essa diferenciação entre história, como disciplina e método distintivo, e histórico, como atributo de processos e práticas que ocorrem no tempo e no espaço, não é apenas um recurso para ressaltar dimensões da articulação entre história e política, mas indica diferentes compreensões sobre a história. Para além da distinção weberiana entre singularidade e generalização, que diferencia analiticamente a causalidade histórica da sociológica, surgiu um vocabulário que contaminou certos segmentos da ciência política: por exemplo, tempo, conjuntura, contexto, evento e seqüência.

No Brasil, os estudos de políticas públicas em perspectiva histórica obtiveram amplo acolhi- 
mento multidisciplinar e grande audiência. Os embates travados com o behaviorismo e as perspectivas não-históricas de análise, tão cruciais para a "virada histórica" no mundo anglo-saxão, não foram muito influentes nas ciências sociais brasileiras. Desse modo, os campos da ciência política, da economia, da história e da sociologia produziram importantes estudos sobre as origens, o desenvolvimento, as continuidades e as mudanças de políticas públicas específicas, , em particular no período republicano. A gênese e o desenvolvimento das políticas sociais de proteção ao trabalhador e das políticas econômicas voltadas para a industrialização foram temas privilegiados nas análises históricas das políticas estatais.

Até a década de 1980, a ênfase foi desvelar políticas estatais específicas em sua dimensão nacional, com poucos empreendimentos comparativos ou de incorporação dos entes subnacionais. Tratava-se de compreender a natureza do Estado brasileiro, seu viés autoritário e centralizador, a modernização econômica e a desigualdade, e refletir sobre as possibilidades de construção de uma ordem democrática. Esse conjunto extenso de trabalhos transitou entre uma narrativa organizada pela teoria e a pesquisa histórica, esta muitas vezes criticada pelos historiadores. Assim, os processos históricos seriam cenários e conteúdos de um argumento teórico e formal que os organizaria e os interpretaria. Nesse sentido, o singular e o contextual, que caracterizam a explicação histórica, foram bases para generalizações e teorizações. Neste diálogo fértil entre política e história, nem sempre explícito ou pacífico, houve reconhecimento mútuo - os cientistas sociais adotaram categorias como periodização e contextualização em seus estudos, e os historiadores, por sua vez, passaram a utilizar categorias analíticas e interpretativas das ciências sociais.

A redemocratização do país trouxe novos temas e problemas de investigação para as ciências sociais, e novos arsenais teóricos e metodológicos adentraram o campo. Novas agendas e problemas de pesquisa e o processo natural de disciplinarização certamente tornou o diálogo entre a história e a ciência política mais complexo em relação àquele estabelecido em décadas anteriores. É preciso reconhecer que, no campo específico da ciência política, a questão "por que a história importa?" (Pierson e Skocpol, 1999) ganhou um sentido particular quando os cientistas políticos perceberam a importância da análise das instituições, e, portanto, a perspectiva históricocomparada passou a ser fundamental. Desse modo, a história tem exercido atração para os que enveredam na investigação de processos e escolhas que se deram "no passado", mesmo próximo, e que influenciam o presente. Por outro lado, o setor de história política passou a enfrentar dilemas do "tempo presente", isto é, entendeu que era necessária uma interpretação histórica para os eventos do presente, mas tinha que manter, ao mesmo tempo, as características distintivas e constitutivas da área. Além disso, os historiadores adentraram também o terreno da ciência política, tratando de temas como eleições, partidos, opinião pública e ações governamentais a partir de suas circunscrições temporais e espaciais (Rémond, 2003). Mas, nesse processo, como sugere Sewell (2005), os historiadores não têm participado ativamente da discussão com as ciências sociais.

A adesão à sentença "a história importa" é constatável pelo número crescente de trabalhos publicados no Brasil e no exterior que comportam temas afins. Porém, a idéia de "voltar para trás e olhar" (Pierson, 2004, p. 47) não é completamente nova, nem tão simples como poderia parecer em princípio, mas é polêmica dentro do próprio neoinstitucionalismo (Hall e Taylor, 2003; Pierson, 2004); e talvez não desfrute de prestígio em certas comunidades acadêmicas que associam a história a métodos qualitativos, com baixa capacidade de formalização e reduzida capacidade de comparação.

Avanços e problemas são assinalados pela literatura que tem buscado refletir sobre o tema e empreender análises historicamente orientadas de políticas. Parte considerável desses avanços advém do crescimento e da visibilidade das análises comparadas e contextualizadas. Esses estudos abordam um número determinado de casos para delinear similitudes e divergências e identificar causalidades nos processos históricos, tais como democratização, efeitos de políticas sociais e conformação dos modernos Estados nacionais (Mahoney e Rueschemeyer, 2003). Também vêm 
produzindo impulsos positivos no campo dos métodos histórico-comparativos. Os avanços e as novas proposições podem ser observados na produção da vertente histórica do novo institucionalismo que se articula, mas não se confunde, com as análises históricas comparadas (Steinmo et al., 1992; Mahoney e Rueschemeyer, 2003). O desafio dessa vertente é procurar explicar processos e resultados políticos a partir de variáveis institucionais, ou melhor, considera as instituições regras do jogo ou limites estruturantes da ação e da interação humana. Aqui, histórico refere-se à visão de que as instituições são produtos de lutas políticas e processos temporais concretos, o que remete ao conceito de dependência de trajetória. Escolhas são feitas em determinadas conjunturas e restringem as chances de trajetórias alternativas em política e políticas, processo esse que varia em contextos diferentes, potencialmente comparáveis. Enfim, existiria uma causalidade social dependente da trajetória percorrida observada no tempo, na bistória (Mahoney, 2001).

Todos se reconhecem vinculados ao movimento que levou a essa virada histórica das ciências sociais e, na área específica da ciência política, os estudiosos têm trabalhado proficuamente com conceitos e processos correlatos na explanação de processos políticos. Alguns autores desejam dar seguimento e aprofundar o debate em torno desse tema, outros preferem não reforçar o vínculo entre as ciências sociais e a história. Nessas diferentes perspectivas, há de se levar em conta que o exame de processos temporais não é apenas uma mudança metodológica, ou aprimoramento técnico, mas também uma mudança teórica (Skocpol e Pierson, 2002; Pierson, 2004; Thelen, 2004). Ou seja, a construção de teorias de continuidade e mudança pressupõe o poder causal de conexões temporais entre eventos. Isso requer conceitos que reconheçam a diversidade dos padrões dessas conexões. Contudo, talvez ainda estejamos nos marcos tradicionais. Skocpol, por exemplo, em meados dos anos de 1980, lembrava que os "clássicos", no seu esforço de compreender os processos de mudança e as estruturas sociais da Europa moderna, se preocuparam em explicar seqüências particulares de eventos históricos buscando a chave para entender as mudanças cruci- ais e os contrastes na formação do mundo moderno (Skocpol, 1985, p. 2)

Alguns autores entendem a história como uma trajetória ou uma ordem particular de eventos que produz resultados mais interessantes analiticamente quanto mais se auto-reforçam e ou se reforçam positivamente. Essa noção de história associada à análise de trajetórias incorre no risco de se criar generalizações simplistas - como, por exemplo, o "passado influencia o presente" - e se enclausurar na busca de causas remotas. Há trabalhos que naturalizam a idéia de dependência de trajetória, além de um uso bastante lato desse conceito, como identificam Mahoney (2000) e Pierson (2004). Este autor sublinha que a história importa nos processos de retroalimentação positiva, nos quais a seqüência é fundamental, e que é preciso identificar não apenas os eventos, mas a ordem temporal em que eles ocorrem, além de estar atento à possibilidade de comparar cursos de eventos diferentes.

Um último comentário é sobre obstáculos para se investigar os aspectos temporais no entendimento de seus resultados em termos de política e políticas. Feitas as ressalvas anteriores, parece que a história como disciplina e arsenal metodológico não tem sido acionada quando proclamam seu papel na análise de políticas. A dependência de trajetória e as dinâmicas de autoreforço, os efeitos de bloqueio e os processos de retroalimentação positiva, entre outros, ao fornecerem um instrumental para analistas de políticas públicas eximiu-os (mas nem todos) do diálogo sistemático com a história. Desse modo, eles iriam além da descrição ou da simples narrativa. A história poderia se tornar simplesmente fonte e arsenal empírico.

Se história é narrativa no tempo, pensar historicamente é indissociável do tempo cronológico, que, por sua vez, não é apenas seqüência temporal de eventos. $\mathrm{Na}$ narrativa histórica os eventos se relacionam entre si e não são facilmente organizáveis e realocáveis. Aqui a distinção disciplinar, sem diálogo, produz um fosso. Vale lembrar que há cada vez mais estudos históricos de qualidade sobre políticas e ações do Estado fora da moldura da ciência política. A pergunta seria como, desprovidos da história, podemos acessar o bistórico? O caminho, creio, é refletir 
sobre os instrumentos que dão acesso ao contexto, à contingência e aos eventos na organização de uma seqüência temporal, o que nos permitiria identificar mecanismos sociais importantes.

\section{BIBLIOGRAFIA}

ABRAMS, P. (1982), Historical sociology. Ithaca, N.Y.,Cornell University Press.

ADAMS, J.; CLEMENS, E. \& ORLOF, A. (2005). Remaking modernity: politics, history, and sociology, Politics, history, and culture. Durham, Duke University Press.

ASHFORD, D. (1992), History and context in comparative public policy: pitt series in policy and institutional studies. Pittsburgh, University of Pittsburgh Press.

COLLINS, R. (1999), Macro bistory: essays in sociology of the long run. Stanford, Stanford University Press.

HALL, P. \& TAYLOR, R. (2003), "As três versões do neo-institucionalismo". Lua Nova, 53: 193-223.

MAHONEY, J. (2000), "Path dependence in historical sociology". Theory and Society, 29: 507-548.

. (2001), The legacies of liberalism path dependence and political regimes in Central America. Baltimore, Johns Hopkins University Press.

(2004) "Comparative-historical methodology". Annual Review of Sociology, 30: 81-101.

MAHONEY, J. \& RUESCHMEYER, D. (2003), Comparative historical analysis in the social sciences. Cambridge studies in comparative politics. Cambridge, U.K./Nova York, Cambridge University Press.

MCDONALD, T. (1996), The bistoric turn in the buman sciences. Ann Arbor, University of Michigan Press.

PIERSON, P. (2004), Politics in time: history, institutions, and social analysis. Princeton, Princeton University Press.
PIERSON, P. \& SKOCPOL, T. (1999), "Why history matters". APSA-CP Newsletter, pp. 2931.

REIS, E. (1998), Processos e escolhas: estudos de sociologia política. Rio de Janeiro, Contracapa.

REMOND, R. (org.). (2003), Por uma bistória politica. Rio de Janeiro, Editora FGV.

SEWELL, W. (2005), Logics of history: social theory and social transformation. Chicago studies in practices of meaning. Chicago, University of Chicago Press.

SKOCPOL, T. (org.). (1985), Vision and method in bistorical sociology. Cambridge, Cambridge University Press.

SKOCPOL, T. \& PIERSON, P. (2002), "Historical institutionalism in contemporary political science", in Ira Katznelson e Helen V. Milner (eds.), Political science: state of the discipline, Nova York, W.W. Norton.

STEINMO, S.; THELEN, K. \& LONGSTRENTH, F. (1992), Structuring politics: historical institutionalism in comparative analysis. Cambridge studies in comparative politics. Nova York, Cambridge University Press.

THELEN, K. (2004), How institutions evolve: the political economy of skills in Germany, Britain, the United States, and Japan. Cambridge studies in comparative politics. Nova York, Cambridge University Press. 